\title{
Note on terminology
}

The vocabulary used to describe ethnic, racial and migration identities is inevitably flawed and contested. In this book we have chosen to use some terms and not others:

Migrant - We use this term to denote those who have moved, either temporarily or permanently, from one country to another. In some research studies, the category 'migrant' refers to those who have citizenship in another country from the one in which they reside. We do not refer to descendants of migrants as migrants unless they themselves have also moved between countries, nor as second- or thirdgeneration migrants.

Asylum seeker - Someone who has left their country of citizenship and applied for asylum (refugee status) in another country but whose application has not yet been decided.

Refugee - The 1951 Refugee Convention defines a refugee as 'any person who, owing to a well-founded fear of being persecuted for reasons of race, religion, nationality, membership of a particular social group or political opinion, is outside the country of his/her nationality and is unable, or owing to such fear, is unwilling to avail himself/ herself of the protection of that country'.

Illegalirregular - Rather than referring to an individual as an 'illegal' migrant we use the terms 'irregular' and 'undocumented' for those without a visa or citizenship as this is usually more accurate, given the frequent changes in law and its interpretation, and individuals' changing circumstances in relation to this. The exception to this use of language is when we refer to the survey work undertaken with Ipsos MORI. In some of the questions for that survey, the term 'illegal/ irregular migrant' was used, as it was seen as more likely to be recognised in everyday conversation. 
Minoritised - In general we do not use the term 'minority ethnic' or 'ethnic minority', except when this is the term used in texts we are discussing or by others we have been in conversation with (for the survey we commissioned, for example, Ipsos MORI use the language of 'white' or 'black and minority ethnic (BME)'). We use 'racialised minorities' and 'racially minoritised' to draw attention to the active processes of racialisation that are involved in terminology.

EU citizen - In most countries of the European Union (EU), citizens of fellow member countries of the EU are referred to as EU citizens, and migrants from countries outside the EU are referred to as 'thirdcountry nationals'. In the UK, common political and public debate has tended to refer to citizens of other EU countries as migrants, despite sharing many similar rights of settlement, work and welfare with UK citizens while the UK remains a member state of the EU. 
argi Bhattacharyya, William Davies, Sukhwant Dhaliwal, Emma Jackson, and Roiyah Saltus - 9781526117946 Downloaded from manchesterhive.com at 04/26/2023 02:23:02PM 